\title{
Analysis on the Causes of Juvenile Suicide and Its Countermeasures
}

\author{
Jiangxin $\mathrm{He}$ \\ Institute of Marxism \\ Xi'an University of Science and Technology \\ Xi'an, China
}

\author{
Yifan Wang \\ Institute of Marxism \\ Xi'an University of Science and Technology \\ Xi'an, China
}

\begin{abstract}
With the fiercer condition of juvenile suicide, students' physical and mental health has gradually become a hot topic in society. The society enjoys rapid development, while the condition of its successors is not good. The young generation is not mature enough to facing the malpractice of modern family, campus and society and cannot get the balance point between themselves and the society, thus they are easily to become unhealthy in mental and psychology. Through the case analysis of the adolescent suicide, it's easy to find that teenagers themselves, families, schools and the whole society are the main power to prevent juvenile suicide.
\end{abstract}

Keywords-adolescent;

suicide

phenomenon; countermeasure

\section{INTRODUCTION}

Adolescents are like flowers of China, and they are the future of times. There is a saying that "Adolescent wisdom is the national wisdom, adolescents rich the country will be rich, adolescents strong the country will be strong". They are like flowers now, but when they grow up, they will become pioneer for China. However, we seem to be concerned about them, but it's not enough at all. The emerging of juvenile suicide cases cannot be prevented at this time, which annoys the society. On October 30, 2016, Urumqi, a student jumped to death; October 23, Guangdong, a college students who graduated just for 3 months fell to death; October 30, Chengdu, a 10-year-old boy, the Grade 5 student of Sichun Normal University Attached Primary School fell to death from 30th floor on March 27, 2017, Wuhan University student $\mathrm{Wu}$ Sheng lost, being founded a month later while dead by suicide. Why tragedies like those happen again and again? Behind these tragic tragedies, the problems of education and management existed in Chinese families, schools and society are exposed that need to be prevented solved.

\section{The CONDITION OF JUVENILE SUICIDE Is DifFICULT TO BE PREVENTED}

According to the survey, the average daily suicide rate of minors in the world is $13 / 100000$, while the average daily suicide rate in China is 25/100000 the most in the world according to some report. Institute of Children and Adolescents, Peking University has published the Report on the Analysis of Suicide in High School Students, which shocked the society by the result one of the five students ever had the thinking of kill him or herself, accounted $20.4 \%$ of all, $6.5 \%$ of whom had planned for suiciding. When we type "Youth student suicide" in the search engine, the relevant information shows that it is as high as three hundred and eighty thousand. Faced with such a data, juvenile suicide phenomenon is no longer special. So what exactly make them behave like that? Pressure on study or life without meaning? If it is because of pressure on study, it is not reasonable because we are doing quality-oriented education. Let alone unmeaningful life, because they are all treasured in their family. Then, what makes these children choose to end their own young and energetic life?

Generally, people will think that it is the result of these children's poor academic performance. But is it the fact? In these adolescents, some had bad academic performance, but there were many outstanding ones, such as the Wuhan University students that we mentioned before who were good at study. Thus, adolescent suicidal behavior is not mainly because of poor academic performance. It is heartbreaking both for the family and their country. Liang Qichao once said in Young China that "Adolescent wisdom is the national wisdom, adolescents rich the country will be rich, adolescents strong the country will be strong".[1] But there are more and more adolescents choosing to end their lives in recent times. If this condition continues to happen, how can we construct our country? So we have to solve this problem urgently.

This paper argues that the main reason for juvenile suicide is on the fundamental issue of life education, and the problem is that we are lacking of it. Many people think that this should be the responsibility of school, while children receive the most education from their families that are easily ignored by parents. In this way, we can get the result that besides the problems lay in themselves, their families, school and the society should be responsible for this situation for the lack of life education.

\section{ANALYSIS FOR THE CAUSES OF SUICIDE}

\section{A. Problem Lies in Themselves}

With the implementation of one-child policy since the reform and opening up, most urban families choose to give birth to only one child. They have a sense of superiority, 
known as "little emperor". However, the problems exist in many aspects. During their growing up, they are attached too much attention and expectation, which deepened their stress and depressed their nature, causing them to close themselves from the outside world. Although many people care about them, they still feel lonely in spirit. They will want to do something to satisfy the families and friends around them. Those children from rural areas cannot get used to new environment in city, which gives them a lot of pressure. If they cannot adjust it appropriately, they will not be able to stand it and will go to extreme in the end.

The motives for juvenile suicide should be analyzed in urgent. In general, suicide can be divided into emotional suicide and intellectual suicide. Adolescents who do emotional suicide are weak in mental and sensitive. They don't know how to adjust their emotion. Such as family psychosis, for those people, maybe stimulation from outside world will make them get out of control in emotion and want to kill themselves. The other is the intellectual suicide. The reason why it is called intellectual suicide is that it is an action with intention and plan. The adolescents who have this behavior usually have unhealthier psychological condition than those emotional ones. It means that they choose to do it because of long-term judgement on the world. And when someone chooses to do something with long-term planning, he or she usually can do it successfully. Long time negative emotions can lead to depression. Adolescents know little about depression and they are under high degree of pressure. Some of them are suffering from depression, while they don't notice it by themselves. Due to the effect of it, they will choose to suicide in the end.

\section{B. Reasons from Their Families}

Family is the first place and the most important one for kids to grow up healthily. While concern to adolescents in China is far from enough and with many problems. Parents tend to meet the material needs of their children while in the contrary ignore their spiritual world. In this way, there will be huge gap between their material and spirit world, which will result in the weakness on characteristics. In China, family education can be divided into four categories: spoiled education, stick education, laissez-faire education, and democratic education. Among the four categories, adolescents who are educated by the first three categories are most likely do suicide. Spoiled education makes children dare not to face the frustration, and they will choose to escape by killing themselves. Stick education is the traditional education method, which believes that "Spare the rod and spoil the child".[2] But in modern society, it is not only illegal, but also can make them feel indifferent about the world. When they cannot find hope, they will choose to kill themselves. Laissez-faire education isn't practical either. Children who are educated by this method will feel that they are not important in their family. So they will have the feeling that whether they live in the world or not makes no sense. When they have nothing to pursue, they will kill themselves. What we most need is democratic education, which helps to educate children in a healthy way. When they meet with some difficulty, they will tell their parents, so that problems can be solved by the guidance of their parents.

\section{Problems from the School}

Generally speaking, at present, the school has opened a course named "Mental Health Education", and psychological counseling room correspondingly. However, actually this course hasn't been taken too serious. Because it cannot increase students' grade point, the counseling room cannot play its function either. Students will have the prejudice that those who have been there are sick in mind. So that fewer and fewer student wants to go there. And this prejudice will prevent those who want to go to counseling room for they are weak in mind and sensitive. They don't want to be called sick in mind. Han Yu said: "The ancient scholar must have teachers. Teachers are those who help to solve problems and confusion. People are not born to know, how can they have no confusion? If they have it, while do not follow the teacher. They cannot solve it in the end."[3] In the process of teaching knowledge and solving confusions, in addition to instilling the knowledge of books, teachers should also pay attention to young people and help them to reduce their pressure in facing academic problems. And have the teachers really focused on the problems above and on the relationship problem solving among students?

China is country with a large population, and with the increasing proportion of young generation, the schools also expand enrollment, so that more and more people will be able to receive education. But it can also add the pressure of teachers and students cannot receive enough care from them because of "Big Class" effect. The teachers are focusing on the academic education, so that they cannot pay much attention to the change on psychological health and its change. If the problems cannot be solved at once, they will be under stress. The educational stress will become psychological one from which adolescents will be suffered.

\section{Social Problems}

Society is good platform for all kinds of people and there will also be many problems followed. Ignoring the life right makes adolescents choose to do suicide easily. With the development of information globalization, both the advantages and disadvantages can be seen in society. The virtual world makes them think that death is only channel for them to be relaxed. Which attracts them most and if they meet some difficulties, they will choose to kill themselves to escape from the real world. It is not only showing the disadvantage of internet world, but also their lacking of responsibility and affordability.

The number of juvenile suicide cases is increasing, or we can also say that this kind of case hasn't been paid much attention to and managed. In this way, those adolescents who have the idea that don't want to live will choose to suicide because of no correct lead. Of them are Phubbing, so they get information from mobile phone, computer and social media in most case. Without enough guide, there will be more negative thinking in their mind which can influence the formation of the correct world outlook, outlook on life and value 
To sum up, for now, the families, environment in the campus and the society are always affecting the growth of young people hasn't been paying too much attention to. So adolescents are living in hidden danger which can burst out at any time.

\section{WAYS TO PREVENT AdOLESCENT SUICIDE.}

Through the analysis of adolescent suicide, we can make sure that when a child chooses suicide, it means that he or she has a very serious mental illness, and ultimately choose to do it through the extreme way. Thus, the importance of life education is obvious. We can effectively curb the spread of juvenile suicide.

\section{A. Focus on Personality Training of Adolescents}

What is easy to be realized but also easy to be ignored is that guiding adolescents. This guiding should be started from their childhood. We should encourage them to make friends instead of self-closed. Good manner is the first step for children to grow up healthily.

Psychiatric hereditary children should face up to this factor, they have to learn to stabilize their emotions. For example, when meet something makes them feel emotional excitement, just calm down and take deep breath or count the number until ten to calm down. When this becomes a habit, they will not be easily stimulated and when something happens, they will be stable in mind. Adolescents should also have a certain understanding of themselves. Zeng $\mathrm{Zi}$ once said: "Everyday trying to examine myself in 3 aspects. Am I loyal when giving other people advice? Am I trustable to my friends? Have I reviewed the knowledge being taught?'[4] Besides this, adolescents should also rethink about their attitudes. If it is negative or have the same trend, don't be hesitate, just talk with friends or parents to try to cure it by doing outside activities. Change life attitude, be positive and be an energetic youth.

\section{B. Parents Should Pay Attention to Their Own Quality- Improvement}

Parents should communicate with each other on how to become qualified educators of their own children to form an environment around themselves.so they can be scientific in the guidance of children to help them build correct value, outlook of life and world outlook. Moreover, for children's education, democratic type are recommended, which is easier for children to say their thinking. For many children, it's not because they don't want to say it out, but because they don't know how to say or to whom they should say. When the confusion is solved, they will not be sensitive. For the transition to democratic education, they should be assured that children being cultivated by spoiled type of education should learn how to accept the frustration. Stick type of education will make the children timid and sensitive. So parents should be more concerned about their children to make them brave and positive. For laissez-faire type, parents should be concerned about their children from the small thing in life to make them feel they are needed and necessary to other people. As the great writer Shakespeare put it: "God made us as we lit the torch, fire is not for torch itself."'[5]

\section{Schools Should Strengthen the Guidance and Care for Students}

Mental Health Education course should be the required course for university study. Students' mental health should be strengthened into practice and this course should be legalized to be written into the education law, so that it can monitor the realization of students' mental health education. Then, educators should train students by activities like "Taking Care of Students", which can be a platform for them to express their puzzles. In this way, not only their problems can be solved, but also they will feel that they are being cared about by people around them. At the same time, the harmonious relationship should be cultivated among students. In recent years, violence in campus happens frequently, and it has a trend of becoming serious, which is bad to the mental health of students. Student team can play an important role in solving this problem. The Student Union can hold activities for going outdoor. In this way, students will not focus on phone and computer, while they will communicate with classmates instead. Reliability will be among them in the end. Though there will be misunderstanding among them for they are at the similar age, they can form an outgoing characteristic in the end.

\section{All the Society Should Pay Attention to the Physical and Mental Health of Students}

Meanwhile much attention should be paid to the juvenile suicide and positive guidance for their growing-up should be carried out. The form of a youth's personality is affected by educations and impact from many aspects. The current policy of reducing the burden should not only focus on primary and secondary school students, but the university students and all young generations. For example, children from rural areas cannot get used to the life there and graduates have to face much pressure in job hunting. The media should also strengthen the positive guidance to young people to spread a down-to-earth positive energy. TV programs like Chinese Poetry Conference and Reader should be produced. We can imagine that if a child who likes to read classic book, he can find spiritual sustenance, how can he easily choose to give up life? And we should even ask the game design company to add something positive to promote positive energy to young generation. In this way, positive guidance can be carried out to some degree.

What is life? For this question, in the long history, we can find answer in Confucianism and Taoism. In Confucianism, there is a saying that "If one doesn't know how to live, how he can know death."[6] And "Every part of body is from parents, don't try to hurt it, which is the start of filial piety."'7] Feng Youlan summed up that: "The starting point of Taoism is to protect body from being hurt."[8] Marx pointed out that "We should first determine the premise of both life and history, which is that if we want to create history, we have to know how to live first."'[9] These ideologists told us clearly the definition of life, but the adolescents' recognition of it is not enough yet. 


\section{CONCLUSION}

Life is so precious, we often say that the child is like the rising sun around 8:00 or 9:00 in the morning. Life is valuable and we cannot find it back if we lose it for once. The death of each teenager is a tragedy for both family and country. Zhu Guangqian also said: "Life is sure a general art, everyone's life history is his own work."[10] We sincerely hope that the phenomenon of juvenile suicide can be attached great importance, the society, school and parents should rethink about their way for education to carry out good life education. In this way, adolescents can have correct outlook on life and know how to respect life.

\section{REFERENCES}

[1] Liang Qichao: Young China, Xi'an: Shaanxi Normal University Press, edition 2010, page 2 .

[2] "Spare the rod and spoil the child", "Stick under the filial son", "Vitex leaves under the good man" and so are folk saying

[3] "The Analects of Confucius, Study", from "The Analects of Confucius Interpretation", Chang Qianhe, Shanghai: Fudan University Press, 2016 edition, page 4.

[4] William Shakespeare: Measure for Measure, Foreign Language Teaching and Research Press, 2016, p. 11.

[5] "The Analects of Confucius, Advanced", from "the Analects of Confucius Interpretation", Chang Qianhe, Shanghai: Fudan University Press, 2016 edition, page 217.

[6] "Principles of Filial Piety", edited by Zhang Shanwen, Ma Chongqi, Shanghai: East China Normal University Press, 2013 edition, the first 1,2 pages.

[7] A Brief History of Chinese Philosophy, Feng Youlan, Beijing: Peking University Press, 2013 edition, p. 66.

[8] "German Ideology", from "Selected Works of Marx and Engels", Beijing: People's Publishing House, 1972 edition, p. 32.

[9] “Talk about Beauty and Cultivation" Zhu Guangwei, Beijing: Qunyan Press, 2014 edition, page 100. 